\title{
The Great Himalaya Trail: A New Nepal Tourism Product with Both Trek Marketing and Development Rationale
}

Lisa Choegyal lisa@mos.com.np



Figure 1: The Great Himalaya Trail map showing the 10 sections. Source: Himalayan Map House and Robin Boustead.

\section{What is the Great Himalaya Trail?}

The Great Himalaya Trail (GHT) is a new and challenging, long-distance trekking route through some of the most breathtaking mountain landscapes on earth. It is made up of a network of existing trails and trade routes that connect neglected valleys and ridges between and beyond the established trekking areas of Annapurna, Langtang and Sagarmatha (Everest). A major objective of the GHT concept is to bring tourism benefits and improve livelihoods in remote mountain communities.

Potentially the longest and highest walking track in the world, the long-term aim of the GHT is to link the six Asian countries of Pakistan, China (Tibet Autonomous Region), India, Nepal, Bhutan and Myanmar, a route that covers more than $4,500 \mathrm{~km}$ of the Great Himalaya range. Its westernmost point is the world's ninth highest peak, Nanga Parbat in Pakistan. Winding past the sacred headwaters of the Ganges in India, it traverses Nepal beneath Annapurna, Sagarmatha and Kanchenjunga, through Darjeeling and Sikkim, then Bhutan and eventually to India's Arunachal Pradesh and Myanmar, ending at Namche Barwa in Tibet. Spectacular views include all of the world's fourteen $8,000 \mathrm{~m}$ peaks. 
In Nepal, the 1,700-km GHT spans the entire length of the country from Darchula and Humla in the West to Taplejung in the East. The high-altitude route offers adventure trekking, combining high pass crossings, trans-Himalayan scenery and alpine valleys. Only a limited number of experienced adventurers are likely to undertake the iconic high trail, which takes some 150 days to complete.

Figure 1 also shows the lower, green GHT route for less extreme trekkers, featuring an unrivalled diversity of scenery, peoples and cultures. This lower route is the major focus for development activities, where the most needy mountain villages are located, and with the widest appeal to softer nature and culture visitor markets. Divided into 10 sections, each section has its own characteristics of verdant valleys, agricultural settlements, mountain scenery, white peaks, wildlife, protected areas, or ancient Buddhist and Hindu cultures. These GHT sections are designed to attract the majority of trekkers, both domestic and foreign, who have only a few weeks for a holiday, encouraging repeat visits and interesting new circuits.

\section{Tourism and Development Opportunities}

Nepal's GHT has already generated considerable stakeholder interest. Led by the Nepal Tourism Board (NTB), Treking Agencies Association of Nepal (TAAN) and Nepal Association of Tour Operators (NATO), it is being adopted by Nepal Tourism Year 2011 (NTY 2011), is offered in trek and adventure operators' brochures, and has attracted extensive media coverage in Nepal, Australia, the USA, the UK, Germany and other major source markets. Robin Boustead has featured the high route in a pictorial guide, trekking guide (Trailblazer 2010) website "greathimalayatrail.com" and maps published in Kathmandu.

Adventure activities in addition to trekking and lodge developments respond to market demand and could include biking, horse riding and upmarket fly-trek options using mountain airstrips. In 2010, American trail-runner Sean Burch ran its length in a record 49 days to help the people of Nepal, improving on Rosie Swales Pope's time of 68 days in 2003. The Crane brothers first ran the Himalaya in 1983 and Peter Hillary led the first traverse in 1980. A GHT celebrity trek led by the veteran Everest climber, Apa Sherpa, is planned for NTY 2011 with the World Wildlife Fund (WWF) to promote trekking, conservation and climate change issues.

Development agencies and non-governmental organisations are seeking to build on this marketing momentum and private sector commitment, grasping the unique opportunity for public-private partnerships to help the poor and disadvantaged people in the Nepal hills. The GHT has significant relevance to Nepal's overall tourism context, government tourism policy and market trends, and responds to Millennium Development Goal (MDG) targets. Donor organisations involved include the Asian Development Bank (ADB), Department 
for International Development (DFID), International Centre for Integrated Mountain Development (ICIMOD), (SNV), The Mountain Institute, United Nations Development Programme (UNDP), (UNEP), United Nations World Tourism Organisation (UNWTO) and WWF amongst others.
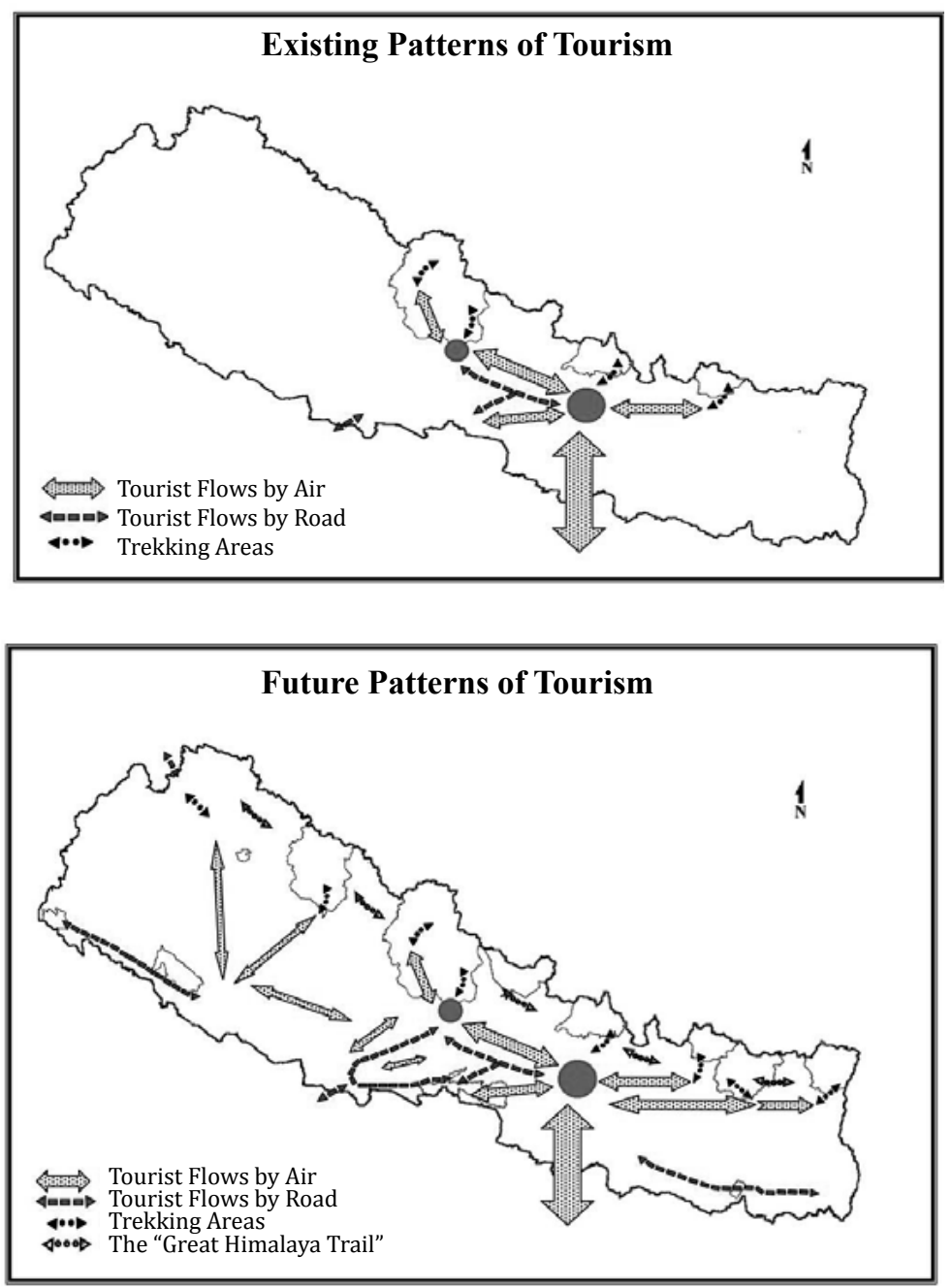

Figure 2: Existing and future patterns of tourism showing "The Great Himalaya Trail" development concept 2001.

Source: Developed during ADB Ecotourism Project TA No 3332 - NEP Final Report Volume 1, 2001 and published in National Ecotourism Strategy and Marketing Programme of Nepal, Nepal Tourism Board 2001 and 2004. 
Providing a significant boost to Nepal's tourism industry, the idea is to channel more tourists and pro-poor tourism investment to under-developed districts, stimulating a range of private sector business, employment and production opportunities for poor mountain communities and providing links with Nepalbased and international tourism operators. New and improved locally managed small and micro enterprises are likely to include lodges, campsites, visitor centres, local produce, handicrafts, porter organizations and guide services to take visitors to monasteries, temples and village homes.

\section{Origins of the Concept}

The idea of the GHT first emerged in the late 1990s as having merit to achieve both marketing and development objectives. The idea came simultaneously from the Nepal tourism industry as a trek marketing tool and from The Mountain Institute (TMI) as a rural development mechanism to improve mountain livelihoods and reduce poverty.

The twin concepts of marketing and development were first pulled together in the ADB Nepal Ecotourism Project in 2001, with a team led by Tourism Resource Consultants. Implementation was constrained by the insurgency that made it difficult for tourists or development workers to visit many parts of the country, but the planning concept remains relevant. The GHT development concept was featured in NTB's National Ecotourism Strategy and Marketing Programme of Nepal 2001 and 2004 (Figure 2), and adopted as a sub-brand in Ministry of Tourism and Civil Aviation (MoTCA)'s Nepal Tourism Vision 2020. In 2004, trekking the GHT was confirmed as a pro-poor tourism initiative in the South Asia Subregional Economic Cooperation (SASEC) Tourism Development Plan, supported by the ADB with the governments of Nepal, Bhutan and India.

With Nepal having the most to gain due to its geography, SNV and ICIMOD took up the concept in 2006. Following a series of consultations and workshops with tourism stakeholders from the public and private sectors, SNV Nepal developed the Great Himalaya Trail Development Programme Concept Document and succeeded in attracting support from DFID (UKAid) private sector funds. DFID has a track record in the sector, having funded MoTCA's Tourism for Rural Poverty Alleviation Programme (TRPAP) with SNV and UNDP based in the NTB from 2001-2007. The TRPAP range of activities are rooted in pro-poor rural tourism development.

With tourism arrivals restored following the 2006 Peace Accord, the Nepalese trek agents need fresh products and new trek circuits. Over $25 \%$ of Nepal's half a million annual visitors go trekking and mountaineering, and $92 \%$ of these 133,000 trekkers are concentrated in the Annapurna, Langtang and Sagarmatha regions (MoTCA 2009). These traditional trek areas suffer from visitor management issues such as perceived overcrowding and new roads impacting on established trekking routes. 


\section{The Current Situation}

The proposed Great Himalaya Trail Development Programme 2010 - 2012 harnesses tourism to improve livelihoods, create employment and bring sustainable development opportunities to remote communities. Nepal is a recognised leader in pro-poor tourism, with long experience using tourism as a driver for development. Designed in mid 2010, the inception phase of the programme is being managed by SNV Nepal with DFID funding, guided by a steering committee comprising representatives from a range of stakeholders chaired by MoTCA.

The programme focus is on settlements along trekking routes in five districts, chosen for their accessibility and market appeal. Pilot developments in Humla and Dolpa are already underway. Three new districts are Gorkha (including Manaslu Conservation Area), lower Solukhumbu (south of Lukla) and Taplejung (including Kanchenjunga Conservation Area). These five areas have been selected as having great potential to attract trekkers off the beaten track, and thus help achieve the project's purpose of spreading tourism benefits, particularly to poor people from excluded groups and women. If successful, other phases are likely to follow.

The proposed Great Himalaya Trail Development Programme has three interrelated elements:

(i) Marketing and promotion of the trail.

(ii) Assisting new and enhancing existing micro and small enterprises along the trail, with improved linkages to tourism businesses.

(iii) Building institutional capacity to better manage tourism at central and district levels.

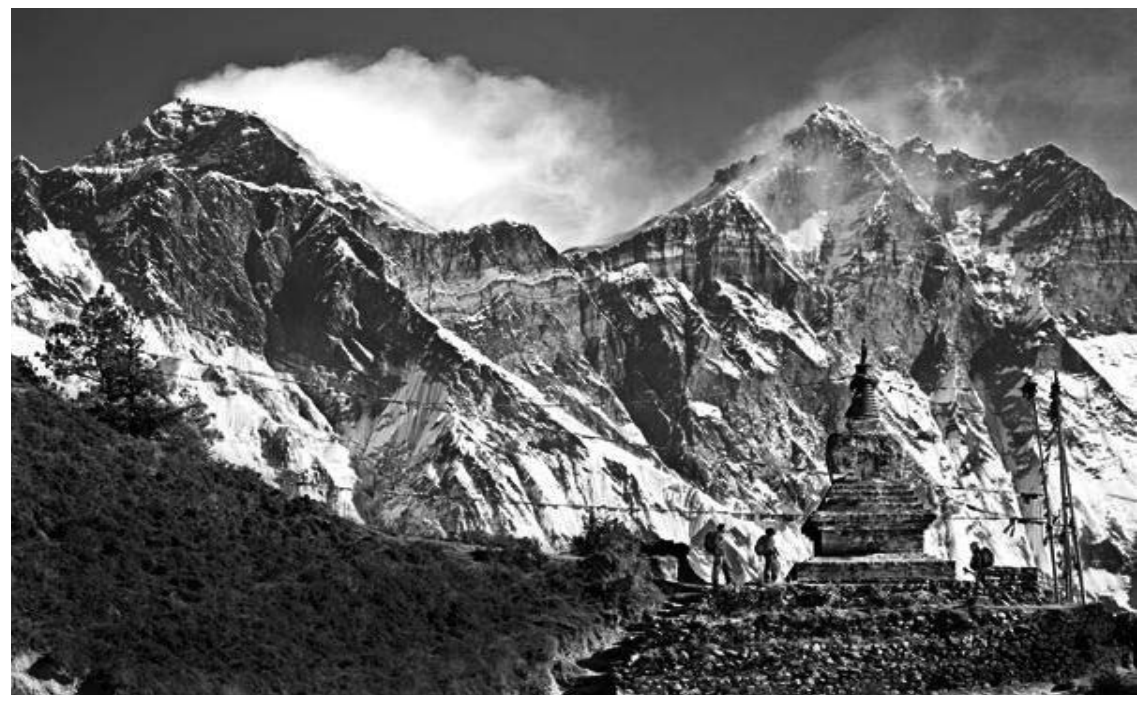

Source: Dmitri Alexander National Geographic Traveller 
The proposed activities will increase awareness and use of new trekking areas, strengthen the capacity of communities to engage in environmentally sound, pro-poor tourism businesses, improve responsible tourism best practice amongst Nepal trek agents and trek guides, improve market linkages and communication links through local government and ensure ongoing management of the Great Himalaya Trail. 